\title{
COST-EFFECTIVENESS ANALYSIS OF INSULIN, SULFONYLUREA, AND SULFONYLUREA- METFORMIN IN TYPE 2 DIABETES MELLITUS
}

\author{
ENDANG LAELASARII,2 ${ }^{1,}$ RANI SAURIASARI ${ }^{1 *}$, AGUSDINI BANUN ${ }^{3}$ \\ ${ }^{1}$ Department of Pharmacy, Faculty of Pharmacy, Universitas Indonesia, Depok, Indonesia. ${ }^{2}$ Department of Procurement Services, Sitanala \\ Hospital, Tangerang, Indonesia. ${ }^{3}$ Directorate General of Pharmacy and Medical Devices, Ministry of Health, Indonesia. \\ Email: rani@farmasi.ui.ac.id \\ Received: 21 April 2017, Revised and Accepted: 13 July 2017
}

ABSTRACT

Objective: This study aims to compare the cost-effectiveness of insulin therapy, sulfonylureas, and combination of sulfonylureas-metformin in patients with type 2 diabetes mellitus in Sitanala Hospital, Tangerang.

Methods: This study employed a cross-sectional to examine the effectiveness and cost of different treatments for Type 2 diabetes mellitus (T2DM) among outpatients at Dr. Sitanala Leprosy Hospital in Tangerang, using cost-effectiveness analysis. Participants had consumed the same drug over the past 4 months and were divided into three groups, as follows: An insulin group ( $\mathrm{n}=29$ ), sulfonylurea group (n=29), and sulfonylurea-metformin combination group $(n=39)$. The effectiveness of treatment was evaluated by considering Hemoglobin A1c (HbA1c) values. The measured cost was direct medical cost.

Results: The results showed that there were more female patients (65.96\%) than male patients with T2DM, and their average age was $50-59$ years. The highest effectiveness was shown in combination in the sulfonylurea-metformin group, with an HbA1c level of 7.48 \pm 1.89 , although the difference was not statistically significant. The direct medical cost of sulfonylurea monotherapy was significantly lower than that of the other therapies. The average cost-to-effectiveness ratio in the insulin group was Rp. 40,866 that in the sulfonylurea group was Rp. 1,369 and that in the combination of sulfonylurea-metformin group was Rp. 2,621 per percentage of effectivity. The incremental cost-to-effectiveness ratio for the sulfonylurea-metformin to sulfonylurea monotherapy treatment was Rp. 16,194 per percentage effectivity.

Conclusion: Based on the analysis performed, sulfonylurea-metformin combination therapy was more cost-effective than either sulfonylurea or insulin monotherapy.

Keywords: Type 2 diabetes mellitus, Analysis of cost-effectiveness, Antidiabetes.

(C) 2017 The Authors. Published by Innovare Academic Sciences Pvt Ltd. This is an open access article under the CCBY license (http://creativecommons. org/licenses/by/4. 0/) DOI: http://dx.doi.org/10.22159/ajpcr.2017.v10s5.23094

\section{INTRODUCTION}

Diabetes mellitus (DM) is a health problem that affects productivity, thereby reducing human resources. This disease not only affects individuals but also a country's entire health system. The International Diabetes Federation (IDF) predicts the number of patients with diabetes will increase to 380 million in 2025 [1]. For Indonesia, IDF predicts an increase in the number of patients from 10.0 million in 2015 to about 16.2 million by 2040 [2]. Diabetes mellitus needs continuous treatment and education for the patients to prevent acute complication and to reduce the risk of long-term complication, so it is necessary to assess the therapy they receive [3]. Proper administration of drugs will help patients to achieve the desired therapeutic effectiveness while avoiding possible side effects, such as hypoglycemia or insulin resistance. The therapeutic effectiveness should be considered in terms of the costs incurred during treatment to determine the optimal type of therapy.

In the era of National Health Insurance, health-care cost system provides treatment financing according to particular treatment packages. Based on the Minister of Health of the Republic of Indonesia's regulation 59 from 2014 on health service tariff standards in health insurance programs, tariff for region 1, class B hospital outpatients for major chronic diseases (with complications) is Rp. 202,500 while for minor chronic diseases, it is Rp. 165,400 [4]. Sitanala Hospital belongs to region 1 , with almost $90 \%$ of patients being covered by the National Health Insurance Scheme. From the data on the 10 most prevalent outpatient diseases in 2014, out of a total of 13,268 visits, DM patients ranked second, with 1,894 visits (14\%). The population of patients with Type 2 diabetes mellitus (T2DM) is 223 patients [5].

The variation in prescribing patterns of drug therapy for T2DM patients among specialist doctors will result in a difference in the cost and outcome of the therapy; thus, it is important to carry out an analysis of the cost-effectiveness of the use of insulin, sulfonylurea, and sulfonylurea-metformin in combination to determine which therapy is the most cost-effective. This pharmacoeconomic study will assist in making choices in the treatment of DM by considering the costeffectiveness of the therapy given. This study aims to compare the cost-effectiveness of insulin therapy, sulfonylureas, and combination of sulfonylureas-metformin in patients with type 2 diabetes mellitus in Sitanala Hospital, Tangerang.

\section{METHODS}

This research involved a descriptive analytical study with a crosssectional design. Research participants were T2DM patients who had received insulin, sulfonylurea, or sulfonylurea-metformin combination for the 4 months before sampling. The patients' blood was sampled for HbA1c measurements. Further assessment of medical expenses for the last 4 months was also carried out. The population of study participants was all T2DM outpatient who visited the Sitanala Hospital. The sample for this study was all patients with T2DM who went to the Sitanala Hospital and met the inclusion criteria. The sampling technique used was purposive sampling. 
Inclusion criteria for this study were as follows: Patients with T2DM receiving insulin therapy, sulfonylurea therapy, or combined sulfonylurea-metformin therapy. The participants had taken their T2DM drugs at the Sitanala Hospital for the past 4 months. Exclusion criteria for this study were as follows: Incomplete patient data, patients diagnosed with anemia, and leprosy patients. The research tools included data collection sheets, patient approval sheets, stationery, and calculation tools. The study materials included medical records, HbA1c test results from the laboratory, laboratory tariff rates, and tariffs on medicines from Pharmacy Installation Sitanala Hospital. The medical records contained drug usage data (name, dosage, and frequency). The cost component measured was the cost of taking the drug over the previous 4 months.

The work of the study began with the selection of preliminary samples, which was performed by screening all medical records of eligible patients according to the inclusion and exclusion criteria. The population of patients who were considered as participants in the study was outpatients of several polyclinics, namely, the internal medicine, nerve, eye, and surgical polyclinics. Any patient who met the inclusion criteria needed to meet the following requirement signing an informed consent form, providing blood samples; blood sampling was performed by Sitanala Hospital nurses, who were appointed by the hospital's ethics committee, blood samples were taken by the clinical laboratory for HbA1c examination, and consenting to the calculating of medical expenses; data on medical expenses were obtained from the Finance Department (cashier) for administration and doctor fees and Pharmacy Installation Sitanala Hospital for drug expenses and the cost of side effects.

The aim of cost-effectiveness analysis (CEA) is to compare the cost incurred by the patient with its effectiveness; in this research, the parameter used was the HbA1c value. Thus, total cost was the sum of all drug costs incurred in the previous 4 months, whereas effectiveness was calculated based on HbA1c measurements from a patient's blood sample after taking medication for at least 4 months. The analysis of sample data in this study included the following: Effectiveness, average cost-to-effectiveness ratio (ACER) (calculated based on the cost of treatment for T2DM patients divided by the effectiveness of drugs in the insulin, sulfonylurea, and combination of sulfonylurea-metformin groups), and incremental cost-to-effectiveness ratio (ICER) (calculated based on the ratio between the cost differences and effectiveness in each therapy group).

\section{RESULTS}

From the data collected, the research participants comprised 223 patients with T2DM, who were grouped based on the inclusion and exclusion criteria. There were 31 patients included in the insulin group were 31 patients, but 2 patients' data were incomplete; the sulfonylurea group included 30 patients, but 1 patient's data were incomplete; and there were 45 people in the combination sulfonylurea-metformin group, but the data were incomplete for 6 patients. Thus, the data taken in this study related to 97 patients. Incomplete data arose because some patients do not take their drugs regularly, although the drugs are administered at community health center or family clinic.

Parametric data were analyzed by one-way analysis of variance (ANOVA) or independent t-test after being tested for normality with the Kolmogorov-Smirnov. Descriptive characteristics of the research participants are given in Table 1. These data were tested using the Chisquare test. The results of statistical analysis showed no significant differences between the insulin, sulfonylurea, and sulfonylureametformin groups.

Most patients were women aged 50-59 years old. Based on the previous research, people with T2DM are usually above 45 years of age [6]. In addition, another research supported this claim by stating that most patients develop DM at 54-65 years of age [7].

By gender, the largest proportion of men was present in the group using combination sulfonylureas-metformin therapy. The IDF diabetes atlas [2] showed the incidence of diabetes mellitus by gender, reporting that there were more men than women with T2DM in 2015, with the numbers reaching 215.2 million and 199.5 million, respectively. In this study, it was found that $96.90 \%$ of patients in the sulfonylurea group had disease comorbidity. Disease complications were most frequent in the sulfonylurea-metformin combination group, at $38.46 \%$, whereas the sulfonylurea group showed the lowest likelihood disease complications.

In this study, HbA1c was employed as the effective clinical parameter to measure patients' blood. The effectiveness of single insulin use therapy and oral antidiabetic drug used for the past 4 months was determined with a threshold of $\mathrm{HbA1c} \leq 6.5$ as the parameter for achieving the therapy target. Insulin groups used in this study include rapid-acting, intermediate-acting, long-acting, and pre-mixed insulin. The types of sulfonylurea included glimepiride, gliclazide, gliquidone, and glibenclamide. Finally, another drug used was used, which was metformin.

Table 2 shows that the treatment for T2DM in Sitanala Hospital did not reach the therapeutic target of $\mathrm{HbA} 1 \mathrm{c} \leq 6.5 \%$. There were no statistically significant differences in the effectiveness levels of the three therapy groups. Clinically, however, the sulfonylurea-metformin group showed better $\mathrm{HbA1c}$ values than the other two treatments did.

Table 1: Characteristics of the study participants based on treatment group

\begin{tabular}{|c|c|c|c|c|}
\hline \multirow[t]{2}{*}{ Parameter } & \multicolumn{3}{|l|}{ Frequency (\%) } & \multirow[t]{2}{*}{ p-value } \\
\hline & Insulin group $(n=29)$ & Sulfonylurea group $(n=29)$ & Sulfonylurea-metformin group $(n=39)$ & \\
\hline Age & & & & 0.006 \\
\hline$<40$ years & 3 (11.11) & $0(0)$ & $0(0)$ & \\
\hline $40-49$ years & $5(18.52)$ & $3(10.34)$ & $6(6.22)$ & \\
\hline 50-59 years & $16(59.26)$ & $11(37.93)$ & $22(59.46)$ & \\
\hline 60-69 years & $3(11.11)$ & 15 (51.72) & $9(24.32)$ & \\
\hline Total & 27 & 29 & 37 & \\
\hline Gender & & & & 0.165 \\
\hline Male & $9(31.03)$ & $5(17.24)$ & $15(38.46)$ & \\
\hline Female & 20 (68.97) & $24(82.76)$ & $24(61.54)$ & \\
\hline Total & 29 & 29 & 39 & \\
\hline Comorbidity & & & & 0.982 \\
\hline Yes & $28(96.55)$ & $29(100)$ & 37 (94.87) & \\
\hline No & $1(3.45)$ & 0 & $2(5.13)$ & \\
\hline Complications & & & & 0.404 \\
\hline Yes & 8 (27.59) & 7 (24.14) & 15 (38.46) & \\
\hline No & $21(72.41)$ & $22(75.86)$ & $24(61.54)$ & \\
\hline
\end{tabular}


Table 2: Parameters of HbA1c effectiveness based on the study group

\begin{tabular}{llllll}
\hline Group & $\mathbf{n}$ & Average difference in HbA1c value (\%) & 95\% CI & p-value \\
\cline { 3 - 5 } & & & Minimum & Maximum \\
\hline Insulin group & 29 & $8.42 \pm 1.73$ & 5.80 & 13.00 \\
Sulfonylurea group & 29 & $8.17 \pm 2.27$ & 4.7 & 14.00 \\
Sulfonylurea-metformin group & 39 & $7.48 \pm 1.89$ & 5.10 & 14.00 \\
Total & 97 & & & & 0.131 \\
\hline
\end{tabular}

Table 3: Cost-comparison analysis based on the research group

\begin{tabular}{lllll}
\hline Group & Cost (Rp.) & $\mathbf{9 5 \%} \mathbf{C I}$ & & \multicolumn{2}{c}{ p-value } \\
\cline { 3 - 5 } & & Minimum & Maximum & $0.000^{\mathrm{a}}$ \\
\hline Insulin & $3,154,830$ & $2,521,097$ & $3,570,789$ & $0.000^{\mathrm{b}}$ \\
Sulfonylurea & 108,894 & 62,101 & 175,631 & $0.000^{\mathrm{c}}$ \\
Sulfonylurea-metformin & 227,761 & 201,319 & 345,283 & \\
\hline
\end{tabular}

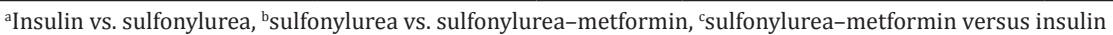

Table 4: ACER and ICER

\begin{tabular}{llll}
\hline Parameter & Insulin group & Sulfonylurea group & Sulfonylurea-metformin group \\
\hline Cost (Rp.) & $3,154,837$ & 108,897 & 227,760 \\
Effectiveness (\%) & 77.20 & 79.56 & 86.90 \\
ACER (Rp./\%) & 40,866 & 1,369 & 2,621 \\
ICER (Rp./\%) & & Dominant & $16,194^{\mathrm{a}}$ \\
Sulfonylurea versus insulin & & Dominant & \\
Sulfonylurea-metformin versus insulin & & & \\
\hline
\end{tabular}

aICER of sulfonylurea-metformin versus sulfonylurea - Rp. 16,194 per percentage effectiveness. ACER: Average cost-to-effectiveness ratio, ICER: Incremental cost-to-effectiveness ratio

Table 5: Differences in HbA1c values based on age, gender, comorbidity, and disease complications

\begin{tabular}{lll}
\hline Parameter & HbA1c value & p-value \\
\hline Age & & \\
$\quad<40$ years & $8.60 \pm 0.70$ & 0.383 \\
40-49 years & $8.05 \pm 1.99$ & \\
50-59 years & $8.13 \pm 1.99$ & \\
60-69 years & $7.36 \pm 2.03$ & \\
>70 years old & - & \\
Gender & & \\
$\quad$ Male & $7.41 \pm 1.61$ & \\
$\quad$ Female & $8.21 \pm 2.09$ & \\
Comorbidity & & \\
$\quad$ Yes & $7.99 \pm 2.10$ & \\
$\quad$ No & $7.37 \pm 0.83$ & \\
Complications & & \\
$\quad$ Yes & $7.57 \pm 1.65$ & \\
No & $8.1 \pm 2.11$ & \\
\hline
\end{tabular}

In the results of observations for the previous 4 months, no reports or incidents related to adverse effects of insulin, sulfonylurea, or combination sulfonylurea-metformin combinations due to drug side effects were found. Thus, costs due to side effects were not considered. In this study, the researchers compared the components of drug costs alone, as the other cost components had fixed values. The results of statistical analysis using one-way ANOVA exhibited significantly different average medication costs for the three treatment groups $(\mathrm{p}<0.001)$. The costs were Rp. 3,154,830 for the insulin group, Rp. 108,894 for the sulfonylurea group, and Rp. 227,761 for the combination sulfonylurea-metformin group.

Statistically, there were significant cost differences between the insulin and sulfonylurea, insulin and combination sulfonylurea-metformin, and sulfonylurea and combination sulfonylurea-metformin groups (Table 3). The results of the ACER calculations are shown in Table 4.
The sulfonylurea-metformin group was more cost-effective than the sulfonylurea and insulin groups. Thus, the combination therapy can be the primary choice in the treatment of T2DM in RSK Dr. Sitanala. This is in line with the research conducted by Abdelaziz et al. which stated that the combination of metformin and glimepiride is more cost-effective in the treatment of T2DM at hospitals in Bengaluru [8].

From the ICER analysis results, there was a cost difference Rp. 16,194 between the combination of sulfonylurea-metformin group compared with the sulfonylurea alone group. The cost of therapy involving a combination of sulfonylurea and metformin is more expensive but provides better effectiveness compared to sulfonylurea alone. Bootman et al. stated that in a CEA, the cost of having the highest effectiveness and the cheapest cost is the main choice; however, if there is a drug that has higher effectiveness and the cost is also greater, effectiveness should have more weight than cost in the decision-making [9]. A drug that is more expensive but more effective than other drugs is more costeffective [10].

The mean differences in HbA1c values in relation to confounding factors can be seen in Table 5. ANOVA was used to test for differences in the variation of age, whereas the t-test was used for gender, comorbidity, and complications. Age variation did not exhibit a significant effect on HbA1c values.

\section{DISCUSSION}

Individuals aged over 45 years are more susceptible to T2DM because there is a decrease in physical activity with increasing age, resulting in abnormalities in the glucose metabolism that will affect the induction of glucose to insulin secretion and insulin resistance [11]. Moreover, increased age will decrease the sensitivity of pancreatic beta cells to the incretin hormone and insulin resistance due to the destruction of pancreatic beta cells, leading to the development of T2DM. Data on the cost component of the insulin, sulfonylurea, and combination sulfonylurea-metformin treatment groups included registration fees, specialist doctor fees, laboratory examination fees, drug costs, and 
the cost of drug side effects. The cost of drugs represented the highest percentage of costs. This finding emerged because the drug costs have the highest unit price. Arnold [10] stated that medical expenses and outpatient expenses are a major component of direct cost, making up $62-90 \%$ of these costs.

Gender did not affect the HbA1c value. The comorbidities present in the study group were hypertension and dyslipidemia. Hypertension is a factor that plays a role in the occurrence of microvascular and macrovascular complications in people with DM. DM has the same risk as coronary heart disease, so dyslipidemia in DM must be managed properly. Decreased cholesterol levels can reduce cardiovascular events in people with DM. Another comorbidity involves patients' use of antiplatelet drugs, such as aspirin. Use of aspirin 75-162 $\mathrm{mg}$ is recommended for the primary prevention of the chronic complications of DM [12]. In this study, the variable of comorbidity did not affect the value of $\mathrm{HbA} 1 \mathrm{C}$ patients.

Previous study found that diabetes with complications resulted in double the cost compared to diabetes alone [13]. Complications in this study were neuritis, diabetic cataracts, and sulcus or gangrene. The results of the statistical analysis showed that the presence or absence of complications in the study group did not affect the HbA1c value. In the United Kingdom, a prospective diabetes study showed that over 9 years, $9 \%$ of DM patients had microvascular complications and $20 \%$ had macrovascular complications; macrovascular complications were the cause of death in patients with diabetes in $75 \%$ of cases. Microvascular complications include neuritis, retinopathy, nephropathy, and peripheral vascular disease. The incidence of complications is directly proportional to the duration of DM and poor blood sugar control.

\section{CONCLUSION}

Treatment with a combination of sulfonylurea-metformin gave a better HbA1c value than treatment with insulin or sulfonylurea alone. Treatment using combination sulfonylurea-metformin therapy is more cost-effective than therapy using insulin or sulfonylurea alone.

\section{REFERENCES}

1. Renuga E, Ramakrishnan SR, Vanitha RN, Thennarasu P, Kannan G. Impact of continuous patient counselling on knowledge, attitude, and practices and medication adherence of diabetec patients attending outpatient pharmacy services. Asian J Pharm Clin Res 2016;9(1):364-9.

2. International Diabetes Federation. IDF Diabetes Atlas. $7^{\text {th }}$ ed. International Diabetes Federation; 2015.

3. Keban SA, Najuah N, Abdillah S. The role of pharmacyst in evaluating and intervening the patients with diabetic neuropathy. Asian J Pharm Clin Res 2017;10(2):127-31.

4. Indonesian Ministry of Health. Peraturan Mentri Kesehatan Republik Indonesia Nomor 59 Tahun 2014 Tentang Standar Tarif Pelayanan Kesehatan Dalam Penyelenggaraan Jaminan Kesehatan. Jakarta: Indonesian Ministry of Health; 2014.

5. Sitanala RD. Laporan Tahunan Tahun Anggaran 2014 Instalasi Rawat Jalan. Tangerang: RSK Dr. Sitanala; 2014.

6. Wahyuni NK, Larasathy LP, Udayani NN. Analisis Efektivitas Biaya Penggunaan Terapi Kombinasi Insulin dan Oho Pada Pasien Diabetes Melitus Tipe 2 Rawat Jalan di RSUD Wangaya. Bali: Universitas Udayana; 2012.

7. Primadiamanti A, Andayani TM. Analisis efektifitas biaya penggunaan insulin di bandingkan kombinasi insulin-metformin pada pasien diabetes melitus Tipe 2. J Farmasi Indones 2009;4:146-55.

8. Abdelaziz MS, Rani HS, Ravindranath S, Shaik R, Kasim M, Salam AA. Pharmacoeconomic evaluation of oral-hypoglicemic agent at hospital in Bangalore. IOSR J Pharm Biol Sci 2015;10:46-50.

9. Bootman JL, Townsand RJ, McGhan WF. Prinsiples of Pharmacoeconomics. Cincinnati, OH: Harvey Whitney Books Company; 1996.

10. Arnold RJ. Drugs Discovery Series No. 13: Pharmacoeconomics from Theory to Practice. New York: CRC Press; 2010.

11. Meneilly G. Pathophysiology of Diabetes in Elderly. United Stated of America: American Society of Health-System Pharmacists Inc.; 2010.

12. Diabetes Care. American Diabetes Association: Standard of medical care in diabetes 2016. J Clin Appl Res Educ 2016;30 Suppl 1:S1-10.

13. Sangam K, Anifa M, Swathi K, Venkateswarlu K, Reddy TR. Evaluation of pharmacoeconomic direct cost in diabetes patients. Asian J Pharm Clin Res 2017;10(4):38-40. 